\title{
IMMUNOPATHOLOGY OF LEISHMANIASIS: AN UPDATE
}

\author{
P. MANSUETO, G. VITALE, G. DI LORENZO, G.B. RINI, S. MANSUETO and E. CILLARI ${ }^{1}$ \\ Dipartimento di Medicina Clinica e delle Patologie Emergenti, University of Palermo; \\ ${ }^{1}$ U.O. di Patologia Clinica, Azienda Ospedaliera “V. Cervello” of Palermo, Palermo, Italy
}

Received December 3, 1007 - Accepted May 23, 2007

Leishmaniasis represents a severe, increasing, public health problem. The perspective of its control is highly dependent on research progress, on therapeutic manipulations of the immune system, and on vaccine development. There is a correlation between the clinical outcome of Leishmania infection and the cytokine response profile. While a protective immune response against Leishmania has been clearly identified to be related to the influence of a type- 1 response and IFN- $\gamma$ production, the precise role of $T$ helper $\left(T_{H}\right) 2$ cytokines in non-healing infections requires further exploration. IL-4 and IL-13 ( $T_{H} 2$ cytokines) can promote disease progression in cutaneous leishmaniasis, whereas IL-4 would appear to enhance protective type- 1 responses in visceral leishmaniasis. Thus, the $T_{H} 1 / T_{H} 2$ paradigm of resistance/ susceptibility to intracellular parasites is probably an oversimplification of a more complicated network of regulatory/counter regulatory interactions. Moreover, the presence of antigen specific regulatory $T$ cell subsets may provide an environment that contributes to the balance between $T_{H} 1$ and $T_{H} 2$ cells. Finally, the involvement of $\mathrm{CD8}^{+} \mathrm{T}$ cells has been described, but the modality of their function in this kind of infection has not been so far elucidated.

Leishmaniasis represents a severe, increasing public health problem (1-2). Moreover, many of the 50 million people who travel from industrialized to developing countries each year report some infective illness associated with their travel, included leishmaniasis, which is endemic in the areas of tropics, subtropics, and southern Europe (3). The perspective of control is still highly dependent on research progresses, to obtain better tools and more cost-effective strategy for vector control and case management, through therapeutic manipulations of the immune system, and vaccine development (4).

Leishmaniasis comprises a group of diseases caused by protozoan parasites of the Leishmania genus. Leishmaniasis is characterized by different clinical manifestations, which are dependent not only on host genetic control, but also on the infecting species, which to date are more than 20 (5).

The parasites which cause the various forms of leishmaniasis in humans are classified in the subgenus Leishmania (L.) or Viannia (V.). Cutaneous leishmaniasis (CL) is caused, in the Old World, by Leishmania (L.) major, Leishmania (L.) aethiopica, and dermotropic Leishmania (L.) infantum, of the Leishmania subgenus; in the New World, by Leishmania (L.) mexicana, Leishmania (L.) amazonensis, Leishmania (L.) venezuelensis, and dermotropic Leishmania (L.) infantum, of the Leishmania subgenus, and Leishmania (V.) braziliensis, Leishmania (V.) guyanensis, Leishmania (V.) lainsoni, Leishmania (V.) naiffi, Leishmania (V.) panamensis, Leishmania (V.)

Key words: cutaneous leishmaniasis, visceral leishmaniasis, $T_{H} 1 / T_{H} 2$ paradigm, cytokines, chemokines, apoptosis 
peruviana, and Leishmania shawi, of the Viannia subgenus. Mucocutaneous leishmaniasis (MCL), or espundia, is caused by Leishmaniasis ( $V$.) braziliensis, and Leishmania (V.) panamensis, whereas visceral leishmaniasis (VL), also known as 'Kala Azar', is caused by Leishmania (L.) infantum in the Mediterranean area, Middle-East and Asian countries, and Leishmania (L.) chagasi in Latin America. Leishmania (L.) mexicana and Leishmania (L.) amazonensis are now regarded as a single specie, due to their genotypic relationships, within the Leishmania mexicana complex, whereas Leishmania (L.) infantum and Leishmania (L.) chagasi, together with Leishmania (L.) donovani, are now regarded as a single specie, due to their genotypic relationships, within the Leishmania donovani complex. After recovery, patients may develop a chronic CL form, called 'Post-Kala Azar Dermal Leishmaniasis' (PKDL), which usually requires long and expensive treatment (6-7).

Leishmania spp. are digenetic parasites, that develop as flagellated motile promastigotes in the gut of blood-sucking female sand flies (Phlebotomus spp. in the Old Word, Lutzomyia spp. in the New World), transmitted into the dermis of the vertebrate host during the ingestion of a blood-meal, and as obligate intracellular non-motile amastigotes in the phagolysosomes of macrophages and dendritic cell lineage of the vertebral hosts. Leishmaniasis is mainly a zoonotic disease and a wide range of mammals act as reservoirs, particularly rodents, edentates and marsupials in CL, wild canines and domestic dogs in zoonotic VL. In anthroponotic VL (widespread in India) man is the sole source of infection for the vector (8-9).

All species of Leishmania infect mice relatively easily, producing diseases facilitating their utilisation as in vivo models, not only to evaluate the host genetic control of infection, but also to determine how immune responses develop and are regulated (10-11).

\section{Immune responses in animal and human leishmaniasis \\ General aspects}

Parasite factors and host mechanisms are inextricably linked with the pathogenesis of leishmaniasis. To initially establish the infection, promastigotes, inoculated with the sandfly saliva, enter macrophages to evade host responses. Progressive intracellular infection by amastigotes depends on the maintenance of macrophages in an inert, deactivated state. At the same time, however, the immunocompetent host is equipped to respond both with non-specific (innate) and antigen-specific (adaptive) cell-mediated mechanisms. These inflammatory responses mediate disease evolution and may (self-healing disease or asymptomatic infection) or may not (non-healing disease) produce the desired clinical end-result $(8,12)$. At the site of infection, innate responses include cells (neutrophils, monocytes, macrophages, natural killer [NK] cells, and dendritic cells), Pattern Recognition Receptors (PPRs, i.e. toll-like receptors), and soluble products (complement, and released cytokines, including interleukin [IL]-1 $\alpha$, IL-12, Tumor Necrosis Factor [TNF]). Innate mechanisms, especially IL-12 secretion, drive the parallel induction of cell-mediated immunity. This complex set of mechanisms leads to the activation of specific $\mathrm{CD}^{+}$and $\mathrm{CD}^{+} \mathrm{T}$ cells. These effector $\mathrm{T}$ cells circulate, are recruited to cutaneous or visceral sites via adhesion molecules and chemokine mechanisms, and, along with influxing blood monocytes, direct local inflammatory responses, including granuloma assembly and lesion development (13-15).

The site of Leishmania infection in the dermis of patients affected by CL is characterized by a massive infiltration of macrophages and chemokines, such as Monocyte Chemoattractant Protein-1 (MCP-1), monokine induced by interferon (IFN)- $\gamma$ (MIG), IFN- $\gamma$-inducible protein 10 (IP-10), and only a low amount of macrophage inflammatory protein $1 \alpha$ (MIP-1 $\alpha)$ (16-17). In skin lesions of patients with self-healing $\mathrm{CL}$, the healing process is facilitated by high levels of MCP-1 expression, whereas high local levels of MIP- $1 \alpha$ are associated with the non-healing form of CL. MCP-1 and IFN$\gamma$ synergistically activate monocytes to clear intracellular parasites, whereas IL-4 abrogates the effect of MCP-1 (16-17). Predominant $T$ helper $\left(\mathrm{T}_{\mathrm{H}}\right)$ 1-type cell responses are associated with IFN$\gamma$-induced macrophage activation, indicating a network of pleiotropic cytokines, in which IL-12, produced by activated antigen presenting cells (APC), such as macrophages and dendritic cells, 
Table 1. Types of CD4+ T-cells and cytokines involved in different forms of leishmaniasis.

\begin{tabular}{|c|c|c|c|c|}
\hline \multirow{2}{*}{ Disease } & \multicolumn{2}{|r|}{ Healing } & \multicolumn{2}{|l|}{ Non healing } \\
\hline & CD4+T-cell & Cytokines & $C D 4+T$-cell & Cytokines \\
\hline \multirow[t]{3}{*}{ Cutaneous leishmaniasis } & $\mathrm{T}_{\mathrm{H}} 1$ & $\begin{array}{c}\text { Leishmania major, mexicana, amazonensis: } \\
\text { IL-12, IL-1 } \alpha \text {, IL- } 18, \\
\text { IL-23, IL-27, IFN- } \gamma, \\
\text { TNF- } \alpha \text {, MIF, IFN- } \alpha \text {, } \\
\text { IFN- } \beta \text {, GM-CSF, IL- } 10 \text {, TGF- } \beta\end{array}$ & $\begin{array}{c}\text { Leishmania major: } \\
\text { excessive } \mathrm{T}_{\mathrm{H}} 2 \text { response } \\
\text { and/or defective } \mathrm{APC} \text { function } \\
\text { and/or defective } \mathrm{T}_{\mathrm{H}} 1 \text { response }\end{array}$ & $\begin{array}{l}\text { IL-4 (?), IL-13, } \\
\text { IL-10, TGF- } \beta\end{array}$ \\
\hline & & & $\begin{array}{l}\text { Leishmania mexicana: } \\
\text { excessive } \mathrm{T}_{\mathrm{H}} 2 \text { response } \\
\text { and/or defective } \mathrm{APC} \text { function } \\
\text { and/or defective } \mathrm{T}_{\mathrm{H}} 1 \text { response }\end{array}$ & $\begin{array}{l}\text { IL-4, IL-13 (?), } \\
\text { IL-10 (?) }\end{array}$ \\
\hline & & & $\begin{array}{l}\text { Leishmania amazonensis: } \\
\text { excessive } \mathrm{T}_{\mathrm{H}} 2 \text { response } \\
\text { and/or defective } \mathrm{APC} \text { function } \\
\text { and/or defective } \mathrm{T}_{\mathrm{H}} 1 \text { response }\end{array}$ & IL-4 (?) \\
\hline \multirow[t]{2}{*}{ Visceral leishmaniasis } & $\begin{array}{c}\mathrm{T}_{\mathrm{H}} 1 \\
\mathrm{~T}_{\mathrm{H}} 2(?)\end{array}$ & $\begin{array}{c}\text { IL-4 (?), IL-12 } \\
\text { (experimental visceral leishmaniasis) }\end{array}$ & $\begin{array}{c}\text { Experimental visceral leishmaniasis: } \\
\text { defective } \mathrm{T}_{\mathrm{H}} 1 \text { response (?) } \\
\text { excessive } \mathrm{T}_{\mathrm{H}} 2 \text { response (?) }\end{array}$ & $\begin{array}{l}\text { IL-4 (?), IL-10, } \\
\text { TGF- } \beta(?)\end{array}$ \\
\hline & $\begin{array}{c}\mathrm{T}_{\mathrm{H}} 1 \\
\mathrm{~T}_{\mathrm{H}} 2(?)\end{array}$ & $\begin{array}{l}\text { IL-2, IFN- } \gamma, \text { IL-12, IL-15, IL-4 (?) } \\
\text { (human visceral leishmaniasis) }\end{array}$ & $\begin{array}{l}\text { Human visceral leishmaniasis: } \\
\text { defective } \mathrm{T}_{\mathrm{H}} 1 \text { response (?) } \\
\text { excessive } \mathrm{T}_{\mathrm{H}} 2 \text { response (?) }\end{array}$ & $\begin{array}{l}\text { IL-4 (?), IL-10, } \\
\text { TGF- } \beta(?)\end{array}$ \\
\hline
\end{tabular}

CD: cluster of differentiation $T_{H} 1:$ Thelper $1 T_{H} 2:$ Thelper 2 APC: antigen presenting cells IL: interleukin IFN- $\alpha$ : interferon- $\alpha$ IFN- $\beta$ : interferon- $\beta$ IFN- $\gamma$ : interferon- $\gamma$ MIF: Migration Inhibitor Factor TGF- $\beta$ : Transforming Growth Factor- $\beta$ TNF- $\alpha$ : Tumor Necrosis Factor- $\alpha$ GM-CSF: Granulocyte Macrophage-Colony Stimulating Factor

shapes the basic response, and IFN- $\gamma$ and other cytokines also participate (18). However, in patients with clinically apparent infections, especially acute VL (see below), $\mathrm{T}_{\mathrm{H}} 1$ - and $\mathrm{T}_{\mathrm{H}}$ 2-type responses are not characteristically polarised, as both activating (i.e. IL-12, IFN- $\gamma$ ) and suppressive (i.e. IL-4, IL-10, IL13, Transforming Growth Factor [TGF]- $\beta$ ) cytokines are detected (19-20). It is possible that in acute leishmaniasis counterbalancing mechanisms are normally produced to curtail the process (19-20). IL4 , IL-10, IL-13 and TGF- $\beta$ are capable of derailing $\mathrm{T}_{\mathrm{H}}$ 1-type responses and deactivating macrophages, thereby moderating tissue injury, but promoting intracellular infection (19-20).

\section{Resolution of infection: the $T_{H} 1$ response}

It is now well established that a protective immune response against $\mathrm{CL}$ is dependent on the development of a potent type- 1 response (15). The general consensus is that IL-12, from activated APC, possibly augmented by other cytokines (IL- $1 \alpha$, IL18, IL-23 and IL-27, as innate mechanism) drives the differentiation and proliferation of $\mathrm{T}_{\mathrm{H}} 1$ cells, which produce, together with NK cells, IFN- $\gamma$, as antigenspecific acquired cell-mediated response (21-23).

Major Histocompatibility Complex (MCH) class II antigen presentation alone is not sufficient to activate $T_{H} 1$ cell responses and ligation of costimulatory molecules (i.e. B7-1/B7-2 and CD40 on the APC with CD28 and CD40L on the $\mathrm{T}_{\mathrm{H}} 1$ cell, respectively) is also a prerequisite (24-25). IFN- $\gamma$ from $\mathrm{T}_{\mathrm{H}} 1$ cells, and probably to a lesser extent $\mathrm{CD} 8^{+}$ $T$ cells (as part of the antigen-specific acquired cellmediated immune response), but also from IL-12 activated NK cells, as part of the innate response, mediate macrophage activation, superoxide $\left(\mathrm{O}_{2}{ }^{-}\right.$ ) and nitric oxide (NO) production, and parasite killing. Although the molecular mechanism of the action of NO on Leishmania is to date unknown, early data suggested that $\mathrm{NO}$ is directly cytotoxic to the parasites (26-27). The NO-pathway thus appears to be a common mechanism of Leishmania killing. Moreover, macrophage leishmanicidal activity, induced by IFN- $\gamma$, has been shown to be enhanced by other cytokines, such as TNF- $\alpha$, Migration Inhibitor Factor (MIF) and type-1 interferons 
(IFN- $\alpha$ subtypes and IFN- $\beta$ subtype), Granulocyte Macrophage-Colony Stimulating Factor (GM-CSF), as well as by CD40/CD40L interactions (28-29).

For the development of an adequate $\mathrm{T}_{\mathrm{H}} 1$ mediated resistance to Leishmania infection, another important pathway is the Fas/FasL interaction. Activated $\mathrm{T}_{\mathrm{H}} 1$ cells induce apoptotic death in target cells expressing the Fas protein (30). Macrophages, infected with Leishmania, upregulates Fas, in response to IFN- $\gamma$, and become susceptible to $\mathrm{CD}_{4}^{+}$ T cell-induced apoptotic death (30-31). Thus, Fasinduced apoptotic death of infected macrophages might limit the number of host cells at the site of infection which are required for amastigote replication (30-31).

Following resolution of infection, concomitant immunity is dependent upon antigen-specific $\mathrm{CD}^{+} /$ $\mathrm{CD} 25^{+}$T-regulatory cells, producing IL-10 and TGF$\beta$, that moderate the activity of $\mathrm{T}$ effectors (32-33). In the absence of persistent infection, protective immunity is significantly reduced (32-33).

Non-healing cutaneous Leishmania major infection: $T_{H}$ 2-dependent or defective $T_{H} 1$ response

The $\mathrm{T}_{\mathrm{H}} 1-\mathrm{T}_{\mathrm{H}} 2$ paradigm of resistance/ susceptibility to intracellular infection is largely based on investigations using Leishmania major. Initial studies have suggested that the resolution or progression of disease is dependent on distinct CD4 ${ }^{+}$ $\mathrm{T}$ cell subsets, $\mathrm{T}_{\mathrm{H}} 1$ and $\mathrm{T}_{\mathrm{H}} 2$, producing the counter regulatory cytokines IFN- $\gamma$ and IL-4, respectively (34-35). However, contradictory reports have been published indicating a disease progression role for IL-4 (36). These studies posed two significant questions: firstly, could other regulatory cytokines be responsible for the immunosuppressive activity previously attributed to IL-4, and/or secondly, could the well documented defective $T_{H} 1$ response play a major role in progressive disease?

Recent studies, using gene-deficient and transgenic mice, have clearly identified other cytokines in addition to IL-4 having major roles in the non-healing response to Leishmania major (36-37). Particularly, IL-13 has been found to act independently of IL-4, and the effects of IL-13 and IL-4 might be additive (37). Other studies suggest that IL-10 is at least as influential as IL-13 and IL-4 in promoting Leishmania major disease progression.
IL-10 might play a key role in the pathogenesis of leishmaniasis, especially in the down-regulation of $\mathrm{T}_{\mathrm{H}} 1$ responses, as supported by the observations of suppression of IL-12 production by APC, and of IFN- $\gamma$ production by $\mathrm{CD}^{+} \mathrm{T}$ and NK cells, and of macrophage deactivation and inhibition of their leishmanicidal functions. T regulatory cells are also significant producers of TGF- $\beta$, which is also partly responsible for suppressing protective responses (36-38).

The inability to mount a $\mathrm{T}_{\mathrm{H}} 1$ response, irrespective of a $\mathrm{T}_{\mathrm{H}} 2$ response, has been attributed to an inability to produce or respond to IL-12, and, therefore, to intrinsic defects in APC function or in $T_{H} 1$ cell development. Defective APC function, attributable to a failure to produce IL-12, may also underlie in a deficient APC IL-1 production (39). As a matter of fact, IL-1 upregulates IL-12 production, as well as MHC class II co-stimulatory molecule expression, and mediates the ability of IFN- $\gamma$ to inhibit $\mathrm{T}_{\mathrm{H}} 2$ response (39).

On the contrary, intrinsic defective $T_{H} 1$ cell development, originally identified as an inability to respond to IL-12, has been associated with a downregulation of $\mathrm{T}_{\mathrm{H}} 1$ cell IL-12R $\beta 2$ expression (40). It is well established that IL-12R $\beta 2$ expression can be downregulated by IL-4 produced by $\mathrm{T}_{\mathrm{H}} 2$, even though IL-4-indipendent mechanisms have also been described (40). A recently described defective co-polarization of the $\mathrm{T}$ cell receptor (TCR) and the IFN- $\gamma$ receptor complex in naive $\mathrm{CD}^{+} \mathrm{T}$ cells during the $\mathrm{APC} / \mathrm{T}$ precursor interaction, would also significantly favour a commitment to $\mathrm{T}_{\mathrm{H}} 2$ development (39-40).

Non-healing cutaneous Leishmania mexicanal Leishmania amazonensis infection: IL-4-dependent

In non-healing cutaneous Leishmania mexicana infection IL-4 appears to exert the major contribution, whereas IL-13 and IL-10 are only partially involved (41). The Cathepsin L-like cysteine peptidase (CPB) has been identified as the likely Leishmania mexicana/Leishmania amazonensis virulence factor inducing IL-4 production (42).

While studies on Leishmania mexicana have clearly shown a major disease exacerbating role for IL-4, that might subvert the development of a $\mathrm{T}_{\mathrm{H}}$ 1-response, similar studies, on the closely related 
parasite Leishmania amazonensis, have suggested an insignificant role for IL-4 in non-healing infection (4344). In this setting, CPB might be directly responsible for the inhibition of $T_{H} 1$ responses, due to the ability of CPB to proteolytically degrade the NF- $\mathrm{BB}$ family of signalling proteins (43-44). Thus, IL-4 independent mechanisms might prevail (43-44).

\section{Paradox of $T_{H} 1$ and $T_{H} 2$ in visceral leishmaniasis}

The dichotomy of $\mathrm{T}_{\mathrm{H}} 1$ and $\mathrm{T}_{\mathrm{H}} 2$ cell responses induced by Leishmania parasites is even less clear in VL. In experimental VL by Leishmania donovani, the disease progression is due to the failure of an appropriate $T_{H} 1$ response, rather than to the $T_{H} 2$ cell proliferation (45). In fact, IL-4 has been shown to have no exacerbating role in murine $\mathrm{VL}$, and, under certain circumstances, it can prime for IL-12 production and a type-1 response (41).

In humans infected with Leishmania donovani high concentrations of IL-10 and IFN- $\gamma$ are detected in the sera at the beginning of infection, which return to the normal range following successful chemotherapy (46-47). By contrast, peripheral blood mononuclear cells (PBMC), stimulated in vitro with Leishmania antigen, produce low levels of IL-10 and IFN- $\gamma$ when collected at the time of the diagnosis, and normal levels when assayed after recovery (46-47). IL-4 and IL-2 are undetectable in the sera, whereas IL-4 is in high concentrations in the supernatants in all the phases of the disease (46). IL-2 is significantly reduced in the supernatants of actively infected patients, returning to the normal level after recovery (46-47). Low sera levels of IL-4 might be related to the high production of IFN- $\gamma$, whereas reduction in IL-2 sera levels might be due to the high sera concentration of soluble IL-2 receptor (sIL-2R) that binds IL-2 with a high affinity mechanism (48). In spite of the similar secretion pattern of IL-10 and IFN- $\gamma$, above reported, the control of infection or complete recovery seems to be associated with an increased production of IL-2 and IFN- $\gamma$ (49-51). Furthermore, IL-10 production correlates with the progression of VL (52), and neutralisation of IL-10 with a specific monoclonal antibody restores $\mathrm{T}$ cell proliferation and IFN- $\gamma$ production in PBMC from acute VL patients (53). In vitro studies have also demonstrated that
IL-12 shifts the responses toward a $\mathrm{T}_{\mathrm{H}} 1$-type and enhances IFN- $\gamma$ production (54). These findings therefore suggest that, in patients with active VL, the cytokine profile is not clearly polarized, and both $\mathrm{T}_{\mathrm{H}}$ 1-like and $\mathrm{T}_{\mathrm{H}}$ 2-like cells appear to proliferate and to be activated $(46,50,55)$. The balance of cytokines at the site of primary activation of the Leishmaniaspecific cells appears to be of major importance for the development of $\mathrm{T}_{\mathrm{H}} 1$ and $\mathrm{T}_{\mathrm{H}} 2$ responses (56-57), even though other unknown factors might influence the cellular immune response. Altogether, data indicate that in symptomatic patients $T_{H} 1$ cytokine production is not depressed, but there is an unresponsiveness to the stimuli of these cytokines, also caused by the high production of IL- 10 . Recently, another lymphokine, IL-15, was studied for its role against infectious diseases (58) and for its ability to enhance both $\mathrm{T}_{\mathrm{H}} 1$ responses, by increasing IFN- $\gamma$ production from NK and T cells (59), and $\mathrm{T}_{\mathrm{H}} 2$ responses, by augmenting IL-5 and IL-13 production (60). In particular, it has been demonstrated that endogenous IL-15 plays a role in the suppression of $\mathrm{T}_{\mathrm{H}} 2$ cytokines in acute VL patients, even though it does not enhance the production of $\mathrm{T}_{\mathrm{H}} 1$ cytokines (61), indicating a potential protective role of IL-15 against leishmaniasis caused by the indirect effect on $T_{H} 1$, due to the restriction of $T_{H} 2$ proliferation (61). Furthermore, it has been demonstrated that the activation of macrophage cultures with IL-15 determines a significant anti-Leishmania activity (62). The killing of Leishmania in macrophages, primed with IL-15, is followed by an increase in the IL-12 synthesis (62). Altogether, these data indicate that IL-15 could have a role as an activator of leishmanicidal activity, directly or indirectly, by inducing IL-12 production.

\section{Non-healing visceral leishmaniasis: $T_{H^{2}}$ independent?}

As already mentioned, the disease progression and the exacerbating role for $\mathrm{T}_{\mathrm{H}} 2$ response and IL4 production during Leishmania donovani infection has yet to be demonstrated. Early studies suggest that the differential production of $\mathrm{T}_{\mathrm{H}} 1$ and $\mathrm{T}_{\mathrm{H}} 2$ cytokines does not control the rate of cure (45), although the production of IFN- $\gamma$ correlates with resistance, $\mathrm{T}_{\mathrm{H}} 2$ cytokines are not so clearly responsible for susceptibility (63). 
According to this point of view, studies in mice have shown that animals deficient in IL-4 and IL-4R $\alpha$ are more susceptible to disease than their wild-type counterparts, suggesting that IL-4 may be protective in some circumstances, and can promote resistance, rather than susceptibility, to intracellular pathogens (64). In addition, IL-4 and IL-4R $\alpha$ signalling are not only essential for optimal clearance of Leishmania donovani from the liver and for limiting infection in the spleen (following primary infection), but also are effective for $\mathrm{T}$ cell dependent chemotherapy, and for vaccine-induced resistance (65). In the absence of IL-4, type- 1 responses and IFN- $\gamma$ production fail to be maintained following chemotherapy or fail to be induced by vaccination (64-65). Other studies indicate that IL-10 is the major immunosuppressive cytokine in VL, although TGF- $\beta$ has also a significant disease-promoting activity (66). Experimental IL-10 inhibition allows activation of $\mathrm{T}_{\mathrm{H}} 1$ cell responses and promotes parasite killing (66-67). Furthermore, while the healing process in susceptible mice is IL12 dependent, IL-10, but not IL-4 or TGF- $\beta$, appears to blunt $\mathrm{T}_{\mathrm{H}} 1$-type responses and to determine fatal outcome of the disease (21).

\section{$T$ cell subset modifications in visceral leishmaniasis}

Although data indicate that Leishmania donovani parasites cause alterations of the immune system, with immune-depression, the exact mechanism by which the parasites induce immune-depression is not clear. In patients with symptomatic Leishmania infantum infection the levels of $\mathrm{CD} 3+, \mathrm{CD}^{+}$and $\mathrm{CD}^{+} \mathrm{T}$ cells are within the normal range $(46,50)$, whereas acute VL patients have markedly reduced levels of memory $\mathrm{T}$ cells $\left(\mathrm{CD}^{+} / \mathrm{CD} 45 \mathrm{RO}^{+}\right)$compared with healthy controls, and these cells returned to the normal levels following successful chemotherapy $(46,50$, 68-69). On the contrary, the number of memory $\mathrm{CD}^{+} \mathrm{T}$ cells is markedly increased in persons with asymptomatic infection and positive leishmanin (or Montenegro) skin test, intradermically performed using a culture of promastigotes as antigen (68). The significant increase of memory $\mathrm{CD}^{+} \mathrm{T}$ cells in this group of patients, their relationship with the positive leishmanin skin test and acquired immunity needs further explanations (68-69). However, T cells are strongly activated in acute VL patients, as indicated by the elevated number of $\mathrm{CD}^{+}{ }^{+} \mathrm{HLA}_{-} \mathrm{DR}^{+}$and by the increase in HLA-DR antigen on these cells (46).

The role of apoptosis and CD8+ $T$ cells in Leishmania infection

Previously, it has been shown, both in mice and in humans, that the induction of $\mathrm{T}$ cell apoptosis could be involved in the defective host-cellular responses to challenge with pathogenic infectious agents (70-73). In experimental VL it has been demonstrated that the infection of a susceptible host results in $\mathrm{CD} 4+\mathrm{T}$ cell apoptosis and a decrease in $\mathrm{T}_{\mathrm{H}} 1$ cytokine production (73). In particular, it has been demonstrated that resistance to Leishmania major depends on apoptotic mechanisms, mainly operating through the Fas (APO-1/CD95) pathway, and singeneic gld and lpr mice, lacking a functional Fas system, fail to heal their lesions (74). Furthermore, in mice infected with Leishmania donovani parasites an increased incidence of $\mathrm{T}$ cell apoptosis in liver and spleen was observed (75). Also in VL patients, both in acute and in healed phases of disease, leukocyte apoptosis seems to be involved. In fact, monocytes and $\mathrm{T}$ lymphocytes from acute VL patients show a significantly higher level of apoptosis compared with that observed in healed subjects. The percentage of apoptotic cells was higher in monocytes than in $\mathrm{T}$ lymphocytes (31). T cells involved in programmed cell death were mainly of CD4+ phenotype $(31,76)$. In particular, the subset $T_{H} 1$, evaluated by chemokine receptor5 (CCR5), was involved in this process and used CD95-mediated mechanism (31). The significant increase in apoptosis of $\mathrm{T}_{\mathrm{H}} 1$-like subset $(15-20 \%$ of CD4+ cells) is in line with the studies carried out in susceptible hosts, showing an enhancement of CD4+ $\mathrm{T}$ cell apoptosis, particularly of $\mathrm{T}_{\mathrm{H}}$ 1-like cells, associated with a decrease in $\mathrm{T}_{\mathrm{H}} 1$ cytokine production (73). Since, $\mathrm{T}_{\mathrm{H}} 1$ cytokines appear to be involved in the protection against leishmaniasis, both in experimental models $(27,73)$ and in human infections (57-59), this deletion of CD4+ $\mathrm{T}_{\mathrm{H}}$ 1-like cells could contribute to the depressed cell-mediated immunity in acute VL patients.

On the contrary, in active human localised CL a higher frequency of cell death in CD8+ T cells than in CD4+ $\mathrm{T}$ cells was detected, and these apoptotic events were very low in patients with self-healing 
lesions (76). Thus, cell death of some T cells could be involved in the failure of cell mediated immunity, responsible for severe immune-depression in the various forms of leishmaniasis.

The amount of data available suggests that $\mathrm{CD} 8^{+}$ $\mathrm{T}$ cells are involved in leishmanicidal activity, and that this activity is modulated by IFN- $\gamma$ and IL-2 secretion (77). Many reports have highlighted a variety of effector mechanisms by these CD8+ T cells, which involves the direct cytotoxic activity, through the perforin/granzyme pathway, and the induction of apoptosis, via Fas/FasL interaction (76-78). They also secrete various cytokines (especially IFN- $\gamma$ ) and chemokines (especially the ones belonging to the C-C group, i.e. Regulated upon Activation, Normal T-cell Expressed, and presumably Secreted [RANTES]), that might have a key role in acquired cell-mediated immunity against the parasite, i.e. by promoting $\mathrm{CD}^{+} \mathrm{T}_{\mathrm{H}} 1$ cell development (78).

Perforin/granzyme-mediated direct cytotoxicity, as well as induction of apoptosis of parasitized macrophages, are candidate mechanisms employed by $\mathrm{CD}^{+} \mathrm{T}$ cells in their effort to limit parasite multiplication (76).

\section{Post Kala Azar dermal leishmaniasis}

In most cases of PKDL, parasites or parasites antigens were observed in all the lesions and were able to induce the formation of an inflammatory infiltrate, consisting of a mixture of macrophages, lymphocytes and plasma cells (79). In patients who had high IFN- $\gamma$ responses to Leishmania antigen in vitro, compact epithelioid granulomas were formed (80). The inflammatory cells were mainly $\mathrm{CD}^{+}$, and IL-10 was the most prominent cytokine found in the lesions (80). However, IFN- $\gamma$ was found in all lesions in varying amounts, whereas the presence of IL-4 was variable (79-80).

\section{CONCLUSIONS}

There is a correlation between the clinical outcome of Leishmania infection and the cytokine response profile. While a protective immune response against Leishmania has been clearly identified as being under the influence of a type-1 response and IFN- $\gamma$ production, the precise role of $\mathrm{T}_{\mathrm{H}} 2$ cytokines in nonhealing infections requires careful exploration (see the summary in Table I).

IL-4 and IL-13 ( $\mathrm{T}_{\mathrm{H}} 2$ cytokines) can promote disease progression in appropriate models of CL, whereas the role of IL-4 is not well defined in VL, and also its ability to enhance protective type- 1 response has been described. Thus the $\mathrm{T}_{\mathrm{H}} 1 / \mathrm{T}_{\mathrm{H}} 2$ paradigm of resistance/susceptibility to intracellular parasites is an oversimplification of a more complicated network of regulatory/counter-regulatory interactions. The role of IL-4 in influencing Leishmania infection awaits a re-evaluation according to the Leishmania species involved, to the host organism used and to the tissue site examined. Moreover, the presence of antigen specific regulatory $\mathrm{T}$ cell subsets may provide an environment that contributes to the balance between $\mathrm{T}_{\mathrm{H}} 1$ and $\mathrm{T}_{\mathrm{H}} 2$ cells.

\section{ACKNOWLEDGEMENTS}

This work was supported by grants from the Italian Ministero dell'Istruzione, dell'Università e della Ricerca (MIUR) (ex-60\%) to Pasquale Mansueto and Enrico Cillari.

\section{REFERENCES}

1. Dantas-Torres F. and S.P. Brandao-Filho. 2006. Visceral leishmaniasis in Brazil: revisiting paradigms of epidemiology and control. Rev. Inst. Med. Trop. Sao Paulo 48:151.

2. Bern C. and R. Chowdhury. 2006. The epidemiology of visceral leishmaniasis in Bangladesh: prospects for improved control. Indian J. Med. Res. 123:275.

3. Steffen R., M. Rickenbach, U. Wilhelm, A. Helminger and M. Schar. 1987. Health problems after travel to developing countries. J. Infect. Dis. 156:84.

4. Murray H.W., J.D. Berman, C.R. Davies and N.G. Saravia. 2005. Advances in leishmaniasis. Lancet 366:1561.

5. Croft S.L., L. Vivas and S. Brooker. 2003. Recent advances in research and control of malaria, leishmaniasis, trypanosomiasis and schistosomiasis. East Mediterr. Health J. 9:518.

6. Thomaz-Soccol V., G. Lanotte, J.A. Rioux, F. Pratlong, A. Martini-Dumas and E. Serres. 1993. Phylogenetic taxonomy of New World Leishmania. 
Ann. Parasitol. Hum. Comp. 68:104.

7. Gramiccia M. And L. Gradoni. 2005. The current status of zoonotic leishmaniases and approaches to disease control. Int. J. Parasitol. 35:1169.

8. Bates P.A. and M.E. Rogers. 2004. New insights into the developmental biology and transmission mechanisms of Leishmania. Curr. Mol. Med. 4:601.

9. Colmenares M., S. Kar, K. Goldsmith-Pestana and D. McMahon-Pratt. 2002. Mechanisms of pathogenesis: differences amongst Leishmania species. Trans. R. Soc. Trop. Med. Hyg. 96:S3.

10. Gumy A., J.A. Louis and P. Launois. 2004. The murine model of infection with Leishmania major and its importance for the deciphering of mechanisms underlying differences in Th cell differentiation in mice from different genetic backgrounds. Int. J. Parasitol. 34:433.

11. Louis J.A., A. Gumy, H. Voigt, P. Launois and M. Rocken. 2003. The use of the murine model of infection with Leishmania major to reveal the antagonistic effects that IL-4 can exert on T helper cell development and demonstrate that these opposite effects depend upon the nature of the cells targeted for IL-4 signaling. Pathol. Biol. 51:71.

12. Vannier-Santos M.A., A. Martiny and W. de Souza. 2002. Cell biology of Leishmania spp.: invading and evading. Curr. Pharm. Des. 8:297.

13. McSorley S., L. Proudfoot, C.A. O'Donnell and F.Y. Liew. 1996. Immunology of murine leishmaniasis. Clin. Dermatol. 14:451.

14. Barbieri C.L. 2006. Immunology of canine leishmaniasis. Parasite Immunol. 28:329.

15. Roberts M.T. 2006. Current understandings on the immunology of leishmaniasis and recent developments in prevention and treatment. Br. Med. Bull. 75:115.

16. Steigerwald M. and H. Moll. 2005. Leishmania major modulates chemokine and chemokine receptor expression by dendritic cells and affects their migratory capacity. Infect. Immun. 73:2564.

17. Ritter U. and H. Moll. 2000. Monocyte chemotactic protein-1 stimulates the killing of Leishmania major by human monocytes, acts synergistically with IFNgamma and is antagonized by IL-4. Eur. J. Immunol. 30:3111.

18. Constantinescu C.S., B.D. Hondowicz, M.M.
Elloso, M. Wysocka, G. Trinchieri and P. Scott. 1998. The role of IL-12 in the maintenance of an established Th1 immune response in experimental leishmaniasis. Eur. J. Immunol. 28:2227.

19. Kemp M., J.A. Kurtzhals, K. Bendtzen, L.K. Poulsen, M.B. Hansen, D.K. Koech, A. Kharazmi and T.G. Theander. 1993. Leishmania donovanireactive Th1- and Th2-like T-cell clones from individuals who have recovered from visceral leishmaniasis. Infect. Immun. 61:1069.

20. Chtanova T. and C.R. Mackay. 2001. T cell effector subsets: extending the Th1/Th2 paradigm. Adv. Immunol. 78:233.

21. Bacellar O., A. D'oliveira Jr., S. Jeronimo and E.M. Carvalho. 2000. IL-10 and IL-12 are the main regulatory cytokines in visceral leishmaniasis. Cytokine 12:1228.

22. Murray H.W., C.W. Tsai, J. Liu and X. Ma. 2006. Responses to Leishmania donovani in mice deficient in interleukin-12 (IL-12), IL-12/IL-23, or IL-18. Infect. Immun. 74:4370.

23. Artis D., L.M. Johnson, K. Joyce, C. Saris, A. Villarino, C.A. Hunter and P. Scott. 2004. Cutting edge: early IL-4 production governs the requirement for IL-27-WSX-1 signaling in the development of protective Th1 cytokine responses following Leishmania major infection. J. Immunol. 172:4672.

24. Elloso M.M. and P. Scott. 1999. Expression and contribution of B7-1 (CD80) and B7-2 (CD86) in the early immune response to Leishmania major infection. J. Immunol. 162:6708.

25. Padigel U.M. and J.P. Farrell. 2003. CD40-CD40 ligand costimulation is not required for initiation and maintenance of a Th1-type response to Leishmania major infection. Infect. Immun. 71:1389.

26. Holzmuller P., R. Bras-Goncalves and J.L. Lemesre. 2006. Phenotypical characteristics, biochemical pathways, molecular targets and putative role of nitric oxide-mediated programmed cell death in Leishmania. Parasitology 132:S19.

27. Liew F.Y., X.Q. Wei and L. Proudfoot. 1997. Cytokines and nitric oxide as effector molecules against parasitic infections. Phil. Trans. R. Soc. Lond. B. 352:1311.

28. Al-Zamel F., F.J. Al-Shammary, S. ElShewemi and R. Soliman. 1996. Enhancement 
of leishmanicidal activity of human macrophages against Leishmania major and Leishmania donovani infection using recombinant human granulocyte macrophage colony stimulating factor. Zentralbl. Bakteriol. 285:92.

29. Nunes M.P., L. Cysne-Finkelstein, B.C. Monteiro, D.M. de Souza, N.A. Gomes and G.A. DosReis. 2005. CD40 signaling induces reciprocal outcomes in Leishmania-infected macrophages; roles of host genotype and cytokine milieu. Microbes Infect. 7:78.

30. Eidsmo L., S. Nylen, A. Khamesipour, M.A. Hedblad, F. Chiodi and H. Akuffo. 2005. The contribution of the Fas/FasL apoptotic pathway in ulcer formation during Leishmania major-induced cutaneous Leishmaniasis. Am. J. Pathol. 166:1099.

31. Potestio M., P. D'Agostino, G.C. Romano, S. Milano, V. Ferlazzo, A. Aquino, G. Di Bella, R. Caruso, G. Gambino, G. Vitale, S. Mansueto and E. Cillari. 2004. CD4+ CCR5+ and CD4+ CCR3+ lymphocyte subset and monocyte apoptosis in patients with acute visceral leishmaniasis. Immunology 113:260.

32. Belkaid Y. 2003. The role of $\mathrm{CD} 4(+) \mathrm{CD} 25(+)$ regulatory $\mathrm{T}$ cells in Leishmania infection. Expert. Opin. Biol. Ther. 3:875.

33. Kariminia A., E. Bourreau, H. Pascalis, P. Couppie, D. Sainte-Marie, F. Tacchini-Cottier and P. Launois. 2005. Transforming growth factor beta 1 production by CD4+CD25+ regulatory T cells in peripheral blood mononuclear cells from healthy subjects stimulated with Leishmania guyanensis. Infect. Immun. 73:5908.

34. Aguilar-Torrentera F. and Y. Carlier. 2001. Immunological factors governing resistance and susceptibility of mice to Leishmania major infection. Rev. Latinoam. Microbiol. 43:135.

35. Sacks D.M and N. Noben-Trauth. 2002. The immunology of susceptibility and resistance to Leishmania major in mice. Nat. Rev. Immunol. 2:845.

36. Noben-Trauth N., R. Lira, H. Nagase, W.E. Paul and D.L. Sacks. 2003. The relative contribution of IL-4 receptor signaling and IL-10 to susceptibility to Leishmania major. J. Immunol. 170:5152.

37. Matthews D.J., C.L. Emson, G.J. McKenzie, H.E. Jolin, J.M. Blackwell and A.N. McKenzie. 2000. IL-13 is a susceptibility factor for Leishmania major infection. J. Immunol. 164:1458.

38. Li J., C.A. Hunter and J.P. Farrell. 1999. AntiTGF-beta treatment promotes rapid healing of Leishmania major infection in mice by enhancing in vivo nitric oxide production. J. Immunol. 162:974.

39. Shankar A.H. and R.G. Titus. 1997. The influence of antigen-presenting cell type and interferon-gamma on priming and cytokine secretion of Leishmania major-specific T cells. J. Infect. Dis. 175:151.

40. Chakir H., A. Campos-Neto, M. Mojibian and J.R. Webb. 2003. IL-12Rbeta2-deficient mice of a genetically resistant background are susceptible to Leishmania major infection and develop a parasitespecific Th2 immune response. Microbes Infect. 5:241.

41. Alexander J. and K. Bryson. 2005. T helper (h)1/ Th2 and Leishmania: paradox rather than paradigm. Immunol. Lett. 99:17.

42. Denise H., K. McNeil, D.R. Brooks, J. Alexander, G.H. Coombs and J.C. Mottram. 2003. Expression of multiple CPB genes encoding cysteine proteases is required for Leishmania mexicana virulence in vivo. Infect. Immun. 71:3190.

43. Ueda-Nakamura T., M. da Conceicao Rocha Sampaio, N.L. Cunha-e-Silva, Y.M. Traub-Cseko and W. de Souza. 2002. Expression and processing of megasome cysteine proteinases during Leishmania amazonensis differentiation. Parasitol. Res. 88:332.

44. Cameron P., A. McGachy, M. Anderson, A. Paul, G.H. Coombs, J.C. Mottram, J. Alexander and R. Plevin. 2004. Inhibition of lipopolysaccharideinduced macrophage IL-12 production by Leishmania mexicana amastigotes: the role of cysteine peptidases and the NF-kappaB signaling pathway. J. Immunol. 173:3297.

45. Kaye P.M., A.J. Curry and J.M. Blackwell. 1991. Differential production of Th1- and Th2-derived cytokines does not determine the genetically controlled or vaccine-induced rate of cure in murine visceral leishmaniasis. J. Immunol. 146:2763.

46. Cillari E., G. Vitale, F. Arcoleo, P. D'Agostino, C. Mocciaro, G. Gambino, R. Malta, G. Stassi, C. Giordano and S. Milano. 1995. In vivo and in vitro cytokine profiles and mononuclear cell subsets in Sicilian patients with active visceral leishmaniasis. Cytokine 7:740.

47. Ansari N.A., S. Saluja and P. Salotra. 2006. 
Elevated levels of interferon-gamma, interleukin-10, and interleukin-6 during active disease in Indian kala azar. Clin. Immunol. 119:339.

48. Vitale G., G. Reina, S. Mansueto, R. Malta, G. Gambino, C. Mocciaro, R. D'Agostino, M. Dieli and E. Cillari. 1992. The significance of serum soluble IL-2 receptor as a marker for active visceral leishmaniasis in Sicilian patients. Clin. Exp. Immunol. 90:219.

49. Cillari E., F.Y. Liew, P. Lo Campo, S. Milano, S. Mansueto and A. Salerno. 1988. Suppression of IL-2 production by cryopreserved peripheral blood mononuclear cells from patients with active visceral leishmaniasis in Sicily. J. Immunol. 140:2721.

50. Cillari E., S. Milano, M. Dieli, E. Maltese, S. Di Rosa, S. Mansueto, A. Salerno and F.Y. Liew. 1991. Reduction in the number of UCHL-1+ cells and IL-2 production in the peripheral blood of patients with visceral leishmaniasis. J. Immunol. 146:1026.

51. Carvalho E.M., R. Badaro, S.G. Reed, T.C. Jones and W.D. Johnson. 1985. Absence of gamma interferon and interleukin-2 production during active visceral leishmaniasis. J. Clin. Invest. 76:2066.

52. Ghalib H.W., M.R. Piuvezam, Y.A. Skeiky, M. Siddig, F.A. Hashim, A.M. el-Hassan, D.M. Russo and S.G. Reed. 1993. Interleukin 10 production correlates with pathology in human Leishmania donovani infections. J. Clin. Invest. 92:324.

53. Carvalho E.M., O. Bacelar, C.E. Brownell, T. Regis, R.L. Coffman and S.G. Reed. 1994. Restoration of IFN-gamma production and lymphocyte proliferation in visceral leishmaniasis. $J$. Immunol. 152:5949.

54. Ghalib H.W., J.A. Whittle, M. Kubin, F.A. Hashim, A.M. el-Hassan, K.H. Grabstein, G. Trinchieri and S.G. Reed. 1995. IL-12 enhances Th1-type responses in human Leishmania donovani infections. J. Immunol. 154:4623.

55. Kurkjian K.M., A.J. Mahmutovic, K.L. Kellar, R. Haque, C. Bern and W.E. Secor. 2006. Multiplex analysis of circulating cytokines in the sera of patients with different clinical forms of visceral leishmaniasis. Cytometry A 69:353.

56. Kemp M., T.G. Theander and A. Kharazmi. 1996. The contrasting roles of CD4+ T cells in intracellular infections in humans: leishmaniasis as an example. Immunol. Today 17:13.

57. Romagnani S. 1997. The Th1/Th2 paradigm. Immunol. Today 18:263.

58. Woldmann T.A. and Y. Tagaya. 1999. The multifaceted regulation of interleukin-15 expression and the role of this cytokine in NK cell differentiation and host response to intracellular pathogens. Annu. Rev. Immunol. 17:19.

59. Lauwerys B.R., N. Garot, J.C. Renauld and F.A. Houssian. 2000. Cytokine production and killer activity of NK/T-NK cells derived with IL-2, IL-15, or the combination of IL-12 and IL-18. J. Immunol. 165:1847.

60. Loza M.J., L. Zamai, L. Azzoni, E. Rosati and B. Perussia. 2002. Expression of type 1 (interferon gamma) and type 2 (interleukin-13, interleukin-5) cytokines at distinct stages of natural killer cell differentiation from progenitor cells. Blood 99: 1273.

61. Milano S., G. Di Bella, P. D'Agostino, C. Barbera, R. Caruso, M. La Rosa, V. Ferlazzo, G. Vitale, C. La Russa, G. Gambino, N. Chifari, S. Mansueto and E. Cillari. 2002. IL-15 in human visceral leishmaniasis caused by Leishmania infantum. Clin. Exp. Immunol. 127:360.

62. D'Agostino P., S. Milano, F. Arcoleo, G. Di Bella, M. La Rosa, V. Ferlazzo, R. Caruso, N. Chifari, G. Vitale, S. Mansueto and E. Cillari. 2004. Interleukin-15, as interferon-gamma, induces the killing of Leishmania infantum in phorbolmyristate-acetate-activated macrophages increasing interleukin-12. Scand. J. Immunol. 60:609.

63. Lehmann J., K.H. Enssle, I. Lehmann, A. Emmendorfer and M.L. Lohmann-Matthes. 2000. The capacity to produce IFN-gamma rather than the presence of interleukin-4 determines the resistance and the degree of susceptibility to Leishmania donovani infection in mice. J. Interferon Cytokine Res. 20:63.

64. Satoskar A., H. Bluethmann and J. Alexander. 1995. Disruption of the murine interleukin-4 gene inhibits disease progression during Leishmania mexicana infection but does not increase control of Leishmania donovani infection. Infect. Immun. 63: 4894. 
65. Stager S., J.Alexander, K.C. Carter, F. Brombacher and P.M. Kaye. 2003. Both interleukin-4 (IL-4) and IL-4 receptor alpha signaling contribute to the development of hepatic granulomas with optimal antileishmanial activity. Infect. Immun. 71:4804.

66. Wilson M.E., B.M. Young, B.L. Davidson, K.A. Mente and S.E. McGowan. 1998. The importance of TGF-beta in murine visceral leishmaniasis. $J$. Immunol. 161:6148.

67. Murray H.W., K.C. Flanders, D.D. Donaldson, J.P. Sypek, P.J. Gotwals, J. Liu and X. Ma. 2005. Antagonizing deactivating cytokines to enhance host defense and chemotherapy in experimental visceral leishmaniasis. Infect. Immun. 73:3903.

68. Gollob K.J., L.R. Antonelli and W.O. Dutra. 2005. Insights into CD4+ memory T cells following Leishmania infection. Trends Parasitol. 21:347.

69. Hailu A., D. van Baarle, G.J. Knol, N. Berhe, F. Miedema and P.A. Kager. 2005. T cell subset and cytokine profiles in human visceral leishmaniasis during active and asymptomatic or sub-clinical infection with Leishmania donovani. Clin. Immunol. 117:182.

70. Estaquier J., T. Idziorek, W. Zou, D. Emilie, C.M. Farber, J.M. Bourez and J.C. Ameisen. 1995. T helper type 1/T helper type 2 cytokines and $\mathrm{T}$ cell death: preventive effect of interleukin 12 on activation-induced and CD95 (FAS/APO-1)mediated apoptosis of CD4+ $\mathrm{T}$ cells from human immunodeficiency virus-infected persons. J. Exp. Med. 182:1759.

71. Dockrell D.H. 2001. Apoptotic cell death in the pathogenesis of infectious diseases. J. Infect. 42: 227.

72. Sereti I., B. Herpin, J.A. Metcalf, R. Stevens, M.W. Baseler, C.W. Hallahan, J.A. Kovacs, R.T. Davey and H.C. Lane. 2001. CD4 T cell expansions are associated with increased apoptosis rates of $\mathrm{T}$ lymphocytes during IL-2 cycles in HIV infected patients. AIDS 15:1765.

73. Das G., H. Vohra, K. Rao, B. Saha and G.C. Mishra. 1999. Leishmania donovani infection of a susceptible host results in CD4+ T-cell apoptosis and decreased Th1 cytokine production. Scand. J. Immunol. 49:307.

74. Conceicao-Silva F., M. Hahne, M. Schroter, J. Louis and J. Tschopp. 1998. The resolution of lesions induced by Leishmania major in mice requires a functional Fas (APO-1, CD95) pathway of cytotoxicity. Eur. J. Immunol. 28:237.

75. Alexander C.E., P.M. Kaye and C.R. Engwerda. 2001. CD95 is required for the early control of parasite burden in the liver of Leishmania donovaniinfected mice. Eur. J. Immunol. 31:1199.

76. Bertho A.L., M.A. Santiago, A.M. Da-Cruz and S.G. Coutinho. 2000. Detection of early apoptosis and cell death in T CD4+ and CD8+ cells from lesions of patients with localized cutaneous leishmaniasis. Braz. J. Med. Biol. Res. 33:317.

77. Tsagozis P., E. Karagouni and E. Dotsika. 2005. Function of CD8+ $\mathrm{T}$ lymphocytes in a self-curing mouse model of visceral leishmaniasis. Parasitol. Int. 54:139.

78. Tsagozis P., E. Karagouni and E. Dotsika. 2003. CD8(+) $\mathrm{T}$ cells with parasite-specific cytotoxic activity and a Tc1 profile of cytokine and chemokine secretion develop in experimental visceral leishmaniasis. Parasite Immunol. 25:569.

79. Sharma M.C., A.K. Gupta, N. Verma, V.N. Das, R. Saran and S.K. Kar. 2000. Demonstration of Leishmania parasites in skin lesions of Indian post kala-azar dermal leishmaniasis (PKDL) cases. $J$. Commun. Dis. 32:67.

80. Ismail A., A.M. El Hassan, K. Kemp, S. Gasim, A.E. Kadaru, T. Moller, A. Kharazmi and T.G. Theander. 1999. Immunopathology of post kala-azar dermal leishmaniasis (PKDL): T-cell phenotypes and cytokine profile. J. Pathol. 189:615. 